\title{
Drug treatment of cerebral vasospasm after subarachnoid hemorrhage following aneurysms
}

Yong-fei Liu ${ }^{1,2^{*}+}$, Han-Cheng Qiu ${ }^{1 \dagger}$, Juan Su ${ }^{1}$ and Wei-Jian Jiang ${ }^{1}$

\begin{abstract}
Cerebral vasospasm (CVS) is a common and severe complication of aneurysmal subarachnoid hemorrhage (aSAH). Despite the improvement in treatment of aSAH, CVS complicating aSAH has remained the main cause of death. CVS begins most often on the third day after the ictal event and reaches the maximum on the 5th-7th postictal days. Several therapeutic modalities have been employed to prevent or reverse CVS. The aim of this review is to summate all the available drug treatment modalities for vasospasm.
\end{abstract}

Keywords: Cerebral vasospasm, Subarachnoid hemorrhage, Aneurysms, Drug treatment

\section{Background}

Posthemorrhagic cerebral vasospasm (PHCV) is a major cause of death and permanent disability in patients with aneurysmal subarachnoid hemorrhage (aSAH), which may account for almost $50 \%$ of the deaths among those surviving in the initial ictus [1]. Despite the improvement in the treatment of aSAH with reduced mortality by almost $50 \%$ over the last 20 years [2], angiographic Cerebral vasospasm (CVS) is very common, affecting up to $70 \%$ of aSAH patients, which has a predictable time course: delayed onset between day 3 and 5 , maximal narrowing between day 5 and 14, and then gradual resolution over week 2-4. Nearly half of these patients, about $30 \%$ of all aSAH survivors, will develop a delayed ischemic neurological deficit (DIND), also called symptomatic CVS [1]. The incidence of symptomatic CVS varies between $17 \%$ and $48 \%$ [3-5]. Although endovascular devices and treatment techniques are continuously developing, these minimally invasive procedures still carry treatment-specific risks. At present drug treatment is still the main therapeutic choice, and this review mainly introduces the recent development of drug treatment.

\footnotetext{
* Correspondence: liu-yong-fei@163.com

${ }^{\dagger}$ Equal contributors

${ }^{1}$ The New Era Stroke Care and Research Institute, The Second Artillery

General Hospital PLA, Beijing 100088, China

${ }^{2}$ Third Military Medical University, Chongqing 400038, China
}

\section{Materials and Methods}

An extensive literature search through the PubMed, Embase and SciFinder database was performed without language restrictions using the following terms: (cerebral vasospasm) AND (aneurysm subarachnoid hemorrhage) AND (drug OR medicine OR pharmacon) AND (review OR animal experimental OR clinical trial). At present, the most commom drugs for preventing and treating cerebral vasospasm were classified into the following drugs: calcium channel blocker, fasudil, magnesium, statins, hormones, phosphoiesterase inhabitor, endothelin-1 antagonists, nitric oxide, heparin and fibrinolysis.

\section{Calcium channel blocker (CCB) Nimodipine}

Nimodipine is a dihydropyridine agent that blocks voltage-gated calcium channels and has a dilatory effect on arterial smooth muscle. It is the only FDA-approved agent for vasospasm with a half-life of about $9 \mathrm{~h}$ [6]. Its beneficial effect on CVS derives most likely from its neuroprotective properties compared to arterial smooth muscle cell relaxation [7]. Nimodipine may achieve favorable results in angiographic response and clinical outcomes as well as low complication rate. In addition, nimodipine may reduce the risk of secondary cerebral ischemia after aneurysmal haemorrhage. Safety and effectiveness of nimodipine was recently shown in a metaanalysis conducted in 2011, in which administration of 
nimodipine was contributed to a significant prevention of CVS after aneurysm rupture $(p<0.00001)$ [8].

Oral administration of $60 \mathrm{mg}$ nimodipine every $4 \mathrm{~h}$ over a period of 21 consecutive days is recommended by the current guidelines of the American Stroke Association $[9,10]$. Some experts have proposed the scheme of $30 \mathrm{mg}$ oral nimodipine every $2 \mathrm{~h}$ is more conducive to alleviate vasospasm, especially for the patients with low blood pressure [11]. But its efficiency and safety is needed to be evaluated. Intra-arterial (IA) nimodipine infusion is an effective and safe treatment for symptomatic CVS [12, 13]. In 2009, one prospective randomized clinical trial showed no difference in ischemia prevention and prognosis improvement between intravenous (IV) and oral administration of nimodipine [14]. In 2011, Onal et al. [15] performed an experiment in rabbits to investigate the comparative effects of nimodipine administrated by several pathways, and their study showed that selective IA administration of nimodipine and intrathecal injection (IT) of nimodipine were better than IV and oral administration for chronic vasospasm following SAH.

Recently a group of randomized controlled experiments showed that topical administration of nimodipine did not significantly improve cerebral blood flow (CBF) following SAH [16]. These findings were not consistent with our previous data which demonstrated that the topical administration of nimodipine significantly alleviated CVS following aSAH detected by transcranial Doppler (TCD).

During the actual clinical practice, we have used nimodipine as the treatment of aSAH, which was common for vascular spasm. The unresolved issue is to determine how nimodipine improves aSAH outcomes and its mechanism of limiting delayed cerebral ischemia (DCI). In the future more fundamental research is needed to clarify the mechanism of nimodipine.

\section{Nicardipine}

Nicardipine is a dihydropyridine agent that selectively inhibits calcium ion inflow into the smooth muscle, which is a potent antihypertensive drug. Due to regional selectivity in cerebrovascular smooth muscle, nicardipine has also been investigated in the treatment of vasospasm following aSAH. However, earlier studies showed that nicardipine may be associated with a poor outcome and mortality in patients with CVS .

IA nicardipine is most commonly used in the treatment of CVS after subarachnoid hemorrhage (SAH) mode, which also brings various complications, including pulmonary oedema, prolonged hypotension and renal failure. Interestingly, given those complications caused by nicardipine and the results of many studies that nicardipine does not improve poor outcomes of CVS, its use in clinical practice is controversial. It should be cautious to use IA nicardipine as the treatment of vasospasm, and physicians should be ready to manage the potential severe adverse effects.

In 2005, Hoh et al. [17] revealed significant improvement in TCD velocity studies $(p<0.01)$ and improved clinical outcomes in $42 \%$ of the patients four days after IA nicardipine treatment, and no drug-related complications were reported. A recent meta-analysis by Huang et al. suggested that the risk of poor outcomes (death, vegetative state, or dependency) was reduced by nicardipine in patients after aneurysmal SAH [18].

Nicardipine is a second-generation dihydropyridinetype CCB that was developed approximately 30 years ago. Therefore, nicardipine may act in neuroprotection as a preventive factor of the CVS due to its vasodilator property and a peculiar cerebrovascular profile [18]. However, considering individual differences of the patients and hypotension complication, clinical application of nicardipine is still limited. Therefore, additional large Phase III trials are required before this therapeutic approach can be introduced into routine use. Modification of the presented conclusion may be justified after publication of the prospective multicentre clinical trials.

\section{Verapamil}

Like nimodipine, the CCB verapamil also blocks voltagegated calcium inflow into the smooth muscle cells of the artery. However, verapamil has been used to treat coronary vasospasm in a long time according to the literatures. Its use in the treatment of refractory coronary spasm is safe and effective, which is also advantageous in availability and low price $[19,20]$. Alana et al. [21] prospectively studied the subjects with vasospasm scheduled for cerebral angiography with possible IA injection of verapamil, and their results refuted earlier reports that suggested IA verapamil was not associated with systemic hemodynamic effects. Mikeladze et al. [22] reported a female case which had selective IA administration of verapamil for the treatment of CVS after severe subarachnoid parenchymal hemorrhage due to the internal carotid artery bifurcation aneurysm, and the result showed good clinical outcomes.

Although verapamil is a $\mathrm{CCB}$, it is not selective to cerebral vasculature. There is a controversy as to the systemic hemodynamic effects of IA verapamil. Some studies have indicated no effect of IA verapamil on systemic blood pressure or heart rate [23]. In contrast, Stuart et al. have demonstrated significant reduction in mean arterial blood pressure several hours after IA injection of verapamil in their retrospective study [20]. Although IA administration of verapamil can theoretically alleviate CVS, its clinical application is limited. Moreover, duration of the pharmacological effects of IA verapamil on the cerebral circulation remains unknown. 
More research is required to evaluate its benefits in preventing delayed ischemic neurological deficits (DINDs) following SAH.

\section{Fasudil}

Fasudil hydrochloride is a Rho kinase inhibitor, which has inhibitory effect on protein phosphorylation. It has been reported that various protein kinases, such as protein kinase $\mathrm{C}$, light chain kinase and Rho-kinase, may play a critical role in the signal transduction pathway of CVS [24]. Thereby fasudil is contributed to a unique and effective anti-CVS effect without significantly lowering blood pressure. Preoperatively prophylactic use of antispasm drugs significantly reduces intraoperative and postoperative complications [25].

Juan Liu et al. [26] investigated the role of fasudil in preventing CVS in extracranial carotid artery stenting. They retrospectively analyzed 178 patients with unilateral carotid angioplasty and stenting (CAS) who were given IV fasudil hydrochloride during the perioperative period. The results showed that local CVS was absent in $80.9 \%$ patients, asymptomatic vasospasm was observed in $17.4 \%$ patients and symptomatic vasospasm in $1.7 \%$ patients via DSA imaging.

Shin-ichi Satoh et al. [27] used canine and rat model to verify validation effect of fasudil in the treatment of vasospasm and proved the effectiveness. It was suggested that hydroxyfasudil was contributed to the potency of fasudil to prevent CVS and hyperviscosity, and the potential utility of hydroxyfasudil as a therapeutic agent for patients with SAH was also suggested. However, Naraoka $\mathrm{M}$ et al. [28] employed the double-hemorrhage rabbit model to investigate whether the combination treatment, consisting of pitavastatin as an inhibitor of RhoA and fasudil as an inhibitor of Rho-kinase, prevented CVS. And the results showed the cross-sectional area of basilar artery were significantly increased only by the combination treatment, and the separate use of fasudil or pitavastatin had no significant effect.

Liu Guang Jian et al. [29] conducted a systematic assessment and meta-analysis on fasudil, which demonstrated that occurrence of CVS and cerebral infarction was greatly reduced by fasudil in SAH patients, and clinical outcomes of the patients (as assessed by the Glasgow Outcome Scale) were significantly improved. Due to the limited number of samples and trials, the conclusion still requires further verification by large randomized controlled clinical trials.

\section{Magnesium}

Magnesium sulfate is first used in pre-eclamptic pregnant women to reduce uterine smooth muscle contractions. It is a noncompetitive calcium antagonist with several important vascular and potentially neuroprotective effects
[30]. Magnesium has the effect of vasodilatation by blocking the voltage-dependent calcium channel and decreasing glutamate release as well as the entry of calcium into the cell [31]. In addition, magnesium also attenuates the effect of various potent vasoconstrictors, such as endothelin 1 , and blocks the formation of reactive oxygen species [32].

These potential effects of magnesium on vasodilation and consequent neuroprotection have driven some investigators to study the role of magnesium in preventing CVS and DCI after SAH. Maintenance of a normal magnesium level is reasonable, but the use of a continuous magnesium infusion does not seem to be supported by the evidence [33]. A trial published showed a trend toward an increase in percentage of patients attaining favorable neurological outcomes in the magnesium sulfate group [34]. However, in 2013, one meta-analysis showed that magnesium did not increase the probability of good neurologic outcomes (risk ratio [RR], 1.02; $95 \%$ confidence interval $[\mathrm{CI}], 0.97-1.07 ; P=.49 ; 12$ trials, $n=2345)$ or decrease the risks of cerebral infarction [35]. Recently another randomized controlled trial showed that the patients with a higher serum magnesium concentration had a reduced incidence of vasospasm indicated by angiography, but it was not statistically significant [36].

The effect of magnesium sulfate in the treatment of aASH is not definite. Early studies have shown that magnesium sulfate is contributed to better outcomes of aASH, but the recent studies demonstrate that magnesium sulfate treatment has no significant effect. Therefore, further research focusing on clinical effect, dosage and side effects, etc., is required in the future.

\section{Statins}

Statins were discovered in Japan by Kuroda and Akira in 1971 [37]. The initial aim was to isolate microbial metabolites capable of inhibiting 3-hydroxy-3-methylglutaryl coenzyme A (HMG-CoA) reductase, the main enzyme responsible for the synthesis of cholesterol. Later, some authors found statins had not only cholesterol-lowering effects but also some pleiotropic effects (eg., downregulation of inflammation, upregulation of endothelial and nitric oxide synthesis) [38]. Statins are HMG-CoA reductase inhibitors, which seem to have an important role in vasospasm prevention. The proposed mechanism of the action of statins involves induction of NO pathway and dilation of cerebral vessels, thereby leading to improved cerebral blood flow [39].

In 2005, two small randomized placebo-controlled studies with a total of 119 patients who received either pravastatin or simvastatin showed a reduction of cerebral artery narrowing, less delayed cerebral ischaemic events and an improvement in functional patient outcomes. DINDs were significantly reduced in patients 
treated with simvastatin. Although many studies have shown that early statins treatment is effective for CVS, its wide use in clinical practice is controversial. In 2010, a randomized, double-blind, placebo-controlled pilot study of simvastatin and a systematic review revealed no significantly beneficial effect of statins in patients with aSAH [40]. In 2013 another trial showed that simvastatin had benefit in reduction of clinical vasospasm and mortality as well as improvement of functional outcomes, but it was not statistically significant [41]. A systematic review and meta-analysis for patients with SAH shows no benefits of statins-use to reduce the incidence of vasospasm, which was quite different from the results of previous meta-analysis [42]. However, whether statin therapy after subarachnoid hemorrhage vasospasm is effective or not remains to be confirmed.

\section{Hormones}

\section{Erythropoietin (EPO)}

EPO is a 165-amino acid sialoglycoprotein. There are few studies on EPO treatment in aSAH, and most aim at anemia treatment after SAH. Early animal studies and in-vitro experiments have suggested that EPO has a neuroprotective role in cerebral ischaemia [43].

A growing body of evidence has been accumulated regarding the employment of EPO in the management of CVS. However, the mechanism of EPO action to decrease occurrence of vasospasm remains poorly understood. Several different mechanisms such as inflammation limitation, apoptosis inhibition, oxidative damage limitation, and neurogenesis upregulation have been postulated to explain EPO's neuroprotective action $[44,45]$.

In 2010, one review revealed that the use of EPO may not necessarily reduce the incidence of vasospasm after $\mathrm{SAH}$, but it may reduce the severity and its eventual outcome [46]. In 2013, a randomized controlled animal study suggested that timely EPO application in SAH was sufficient to prevent delayed proximal CVS, but the doses were insufficient to improve microcirculation or show directly neuroprotective effect [47].

EPO treatment in CVS after SAH still stays in the animal experiment level, and a large number of prospective clinical studies are lack. Although the number of patients investigated is smaller, this treatment approach may be a promising option in the acute phase of aSAH.

\section{Estrogen}

Estrogen, specifically $17 \beta$-estradiol (E2), possesses powerful vasodilatory, anti-inflammatory, and neuroprotective properties. Though its current use remains limited to in-vivo animal models of experimental SAH, E2 has potential therapeutic implications for ameliorating the DINDs which follow aneurysmal SAH [48]. Derived from cholesterol, E2 is a powerful vasodilator with the potential to prevent or reverse the vasoconstriction which occurs in CVS. Some experiments have shown that estrogen promotes vasodilatation by three mechanisms: (1) attenuating the up-regulation of endothelin-1 receptors after $\mathrm{SAH}$ as cited above [49]; (2) inducing the up-regulation of L-type calcium ion channels of smooth muscle cells; (3) decreasing SAH-induced inducible nitric oxide synthase (iNOS) expression, and normal endothelial nitric oxide synthase (eNOS) expression [50]

It is suggested that E2 may have neuroprotective properties as follows (1) E2 decreases expression of the critical proinflammatory cytokine, tumor necrosis factor $\alpha(\mathrm{TNF} \alpha)$, by reducing activity of c-JunN-terminal kinase (JNK) [51]; (2) E2 increases expression of the antioxidant thioredoxin (Trx) in a cGMP-dependent manner [52]. Trx decreases oxidation damage and inhibits apoptosis; (3) Neuroglobin (Ngb) is a protein which regulates neuronal oxygen homeostasis by binding to oxygen with a higher affinity than hemoglobin [53]. Recently, we found that, in neurones, Ngb was pivotal for hormone-induced anti-apoptotic effects against $\mathrm{H} 2 \mathrm{O} 2$ toxicity, which may protect brain tissue from oxidative inflammatory injury [54], while E2 increased Ngb expression.(4)E2 has been found to exert antiapoptotic effects through upregulation of adenosine A2a receptor (A2aAR) and extracellular signal-regulated kinases 1 and 2 (ERK1/2) expression [55].(5)The current in vivo evidence presented by Kao et al. [56] implicates Akt signaling pathway in E2-mediated neuroprotection.

Estrogen possesses powerful vasodilatory, antiinflammatory, and neuroprotective properties, but its current use in CVS remains limited to animal models of experimental SAH. E2 has been successfully used in clinical treatment of CVS and DCI following SAH, but a lot of clinical studies are also required to provide robust evidence [48].

\section{Phosphodiesterase inhibitors Milrinone}

Milrinone is a phosphodiesterase III inhibitor that affects cyclic adenosine monophosphate (cAMP) pathways with both inotropic and vasodilatory effects. Its first use in CVS after intracranial aneurysm rupture dated back to 2001 [57]. IA milrinone is a safe and effective treatment of CVS after aSAH. A study investigating the effects of milrinone in 14 patients reported a significant improvement of vasospasm assessed by angiographic control $(p$ $<0.0001)$ [58].

The specific mechanism of milrinone is unclear. Many authors agree it can improve cerebral microcirculation, without changing cardiac output. Some authors also propose milrinone acts through anti-inflammatory pathway to alleviate CVS [24]. Saurabh et al. [59] reported a 
patient with severe vasospasm who was treated with continuous IA administration of nimodipine combined with milrinone and excellent result was achieved. Thus they proposed higher dose of these drugs may be used to effectively control severe CVS.

Although it has been showed that continuous IA injection of milrinone, especially combined with other drugs, is effective in relieving CVS, the side effect of hypotension makes its clinical application very limited. This risk is to thwart the favorable vasodilatory effect on cerebral blood flow. More prospective studies are needed to study which dose is safe and the most effective to patients.

\section{Papaverine}

Like milrinone, papaverine is a phosphodiesterase inhibitor. The use of papaverine as a vasodilator was instigated by the observation during surgery that papaverine, when applied directly on the arterial wall, relieved arterial vasospasm during aneurysm surgery. For a long time, papaverine has been widely employed in IA vasodilator therapy procedures. However, in the current clinical practice, it is infrequently used given concerns about potential neurotoxicity, including transient or permanent monocular blindness, mydriasis, transient hemiparesis, seizures, gray matter necrosis, cardiac dysfunction, respiratory arrest [60], increased intracranial pressure and irreversible brain tissue damage [61]. IV administration of papaverine is not favorable for CVS because of its vasodilatory effect on the peripheral vasculature and the transient nature of its efficacy [62].

Complications of papaverine make its use in clinical practice very limited. Since papaverine relieves spasm more obviously, some surgeons still use it to ease CVS during operation. Future clinical use of papaverine to treat CVS, and what dose of papaverine can maximize its effect with minimum complications still need further research.

\section{Cilostazol}

Cilostazol is an anti-platelet drug. It inhibits phosphodiesterase activity of platelet and vascular smooth muscle, thereby increasing its anti-platelet effect and vasodilator effect of cAMP concentration. Niu et al. [63] conducted a systematic review and meta-analysis on the treatment of aSAH patients and found cilostazol significantly decreased the rate of symptomatic CVS $(p<0.001)$, severe CVS $(p=$ $0.007)$, CVS-related cerebral infarcts $(p=0.001)$, and poor outcomes, defined as modified Rankin Scale score of at least 3 at follow-up $(p=0.011)$. Based on this metaanalysis, cilostazol appears to reduce CVS-related morbidity following aSAH without affecting its mortality.

Cilostazol alleviates CVS, but the specific mechanism is unclear. The effect is supported by Shimamura et al.'s study [64] in which cilostazol is used to prevent phenotypic transformation of smooth muscle cells (SMC) along with requisite experimental evidence.

To conquer CVS in its complexity, it is necessary to elucidate its general, underlying mechanism. Additionally, studies with longer follow-up and more detailed functional measurements are required to determine the effect of cilostazol on neurocognitive outcomes following aSAH.

\section{Endothelin-1 antagonists: clazosentan}

It is widely accepted that interaction between ET-1 and $\mathrm{NO}$ is critical for maintaining adequate cerebral vascular dilatation and sufficient cerebral blood flow during Asah [65]. Clazosentan is one of the most promising pharmacological agents employed for the prevention or reversal of CVS. Animal studies have demonstrated that clazosentan is a competitive endothelin-1 receptor antagonist [66]. It is reported that clazosentan prevents CVS and improves outcomes of aSAH in a dose-dependent manner [67].

In 2013, Shen et al. [68] examined whether clazosentan treatment after aneurysmal SAH significantly reduced the incidence of DINDs and DCI and improved outcomes in a meta-analysis study. The results showed that clazosentan treatment after aneurysmal SAH significantly reduced the incidence of the vasospasm-related DINDs and DCI. However, subsequently a randomized, double-blind, placebo-controlled study [69] claimed that clazosentan did not significantly decrease mortality/ vasospasm-related morbidity and increase poor functional outcomes in patients with aneurysmal SAH undergoing surgical clipping.

As the treatment of CVS after aSAH, clazosentan is still controversial, and there is still a long way to go for its wide use in clinical practice. Further study is required to elucidate the dissociation between vasospasm-related morbidity and outcomes.

\section{Nitric oxide (NO)}

$\mathrm{NO}$ is a key signaling molecule in the regulation of cerebral blood flow. Reduced NO in blood and cerebrospinal fluid is a possible mechanism underlying CVS. Hemoglobin released following aneurysmal rupture inhibits NO production by endothelial NO synthase and decreases NO concentration for smooth muscle cells, leading to vasoconstriction [70]. It has been shown that the presence of hemoglobin and its degradation products disrupt signaling between the vascular endothelium and the underlying smooth muscular layer [71]. It has been demonstrated that NO constitutes a potent endogenous vasodilator, which directly acts on vascular smooth cells, causing vascular relaxation [72]. In addition, $\mathrm{NO}$ also has neuroprotective function [73]. 
Earlier studies have demonstrated that decrease of cerebrospinal fluid NO metabolites is observed within $10 \mathrm{~min}$ after aSAH, which is associated with vasoconstriction [74]. This is thought to be secondary to destruction of nitric oxide synthase NOS function by haemoglobin. Decreased NO bioavailability is also caused by the reaction of cerebral $\mathrm{NO}$ and superoxide anions to produce peroxynitrite [75].

Despite the controversies about NO dysfunction after aSAH, animal evidence has indicated that increasing cerebral NO levels either directly using inhaled NO or indirectly using $\mathrm{NO}$ donors has neuroprotective effects. More prospective randomized controlled experiments are required in the future, and more in-depth research on the clinical application of NO is necessary to provide a more reliable basis for its clinical application.

\section{Heparin}

Heparin is a pleiotropic drug, which has many effects on antagonizing molecular mechanisms of secondary brain injury after aSAH, including endothelin mediated vasoconstriction, the activity of free radicals and antifibrotic effects. A recent study has revealed that low-dose intravenous heparin infusion in patients with aSAH may reduce occurrences of symptomatic vasospasm and infarcts with high safety and efficacy [76]. An doubleblind, randomized comparison of enoxaparin versus placebo has showed that enoxaparin may reduce CVS and ischemia following SAH (Hunt Hess grades I - III) [77]. However, more trials about dose and safety assessment of heparin after aSAH will be needed to reduce or prevent related complications and improve outcomes.

\section{Fibrinolysis}

The severity of CVS may be associated with the volume and distribution of the subarachnoid clots. Intraventricular fibrinolysis has been clinically tested to faster clearance of subarachnoid clots since the early 1990s. Intracisternal administration of low-dose rt-PA for the prevention of CVS after SAH has been demonstrated safe and effective [78]. Recently, a randomized, openlabel phase II study on concomitant low-frequency head-motion therapy and intraventricular rt-PA has been administrated in patients after surgical or endovascular treatment for aSAH, with effective subarachnoid clot reduction, despite a poor effect on radiographic vasospasm, cerebral infarction, or neurological outcome [79]. Though clearance of subarachnoid clots to prevent CVS has been accepted, optimal administration and dosage of fibrinolysis still need to be established.

CVS is a potentially devastating complication that occurs in nearly half of patients who survive within the first $24 \mathrm{~h}$ after aSAH from a ruptured cerebral aneurysm. Subsequent DCI and/or DINDs are contributed to death of these patients. Early prevention and/or treatment of CVS are very important. At present, there are many CVS medications, including calcium channel blockers, phosphodiesterase inhibitors, endothelin antagonist-1, hormones, nitric oxide preparation, etc. Administration is also various, including oral, intra arterial injection, intravenous injection, intrathecal injection, etc. However, oral administration of nimodipine is still a valid approach for the treatment of CVS, which is also the only FDA-approved agent for treatment of vasospasm. The pathogenesis of CVS is a complex process, which is still not very clear. Thus the treatment is relatively difficult. During clinical practice, clinicians rarely use a single drug, and the combined use of two or more drugs is more common. Transluminal balloon angioplasty is probably a more durable intervention, and posterior cerebral artery may also be amenable to angioplasty. Angioplasty should be considered a complementary choice to intraarterial vasodilator therapy; angioplasty should be reserved for proximal vessels and vasodilator therapy is more useful for distal or diffuse disease. Although these IA vasodilators available may increase vessel diameter, there is still lacking convincing evidence about improvement in clinical outcomes of the patients.

\section{Conclusion}

Vasospasm still represents a challenging problem after aSAH. Its pathogenesis is not clear, although there have been many researches on the treatment of CVS. There are abundant treatment schemes, but only oral nimodipine is proved to be effective. Several IA vasodilators are also available, but they merely increase the diameter of blood vessels without robust evidence of improving clinical outcomes of the patients. This discrepancy may be explained by the fact that vasospasm is not the sole factor responsible for poor functional outcomes. More indepth study on the pathogenesis of CVS and targeted research of the effective treatments are required, so as to improve poor outcomes of the patients and reduce the related mortality and morbidity of CVS.

\footnotetext{
Abbreviations

CVS: Cerebral vasospasm; aSAH: Aneurysmal subarachnoid hemorrhage; PHCV: Posthemorrhagic cerebral vasospasm; DIND: Delayed ischemic neurological deficit; SAH: Subarachnoid hemorrhage; CCB: Calcium channel blocker; IA: Intra-arterial; IV: Intravenous; IT: Intrathecal injection; CBF: Cerebral blood flow; TCD: Transcranial Doppler; DCl: Cerebral ischemia; CAS: Carotid angioplasty and stenting; HMG-CoA: 3-hydroxy-3-methylglutaryl coenzyme A; EPO: Erythropoietin; iNOS: nitric oxide synthase; eNOS: Endothelial nitric oxide synthase; TNFa: Tumor necrosis factora; JNK: c-JunN-terminal kinase; Trx: Thioredoxin; Ngb: Neuroglobin; A2aAR: A2a receptor; ERK1/

2: Extracellular signal-regulated kinases 1 and 2; CAMP: Cyclic adenosine monophosphate; NO: Nitric oxide.
}

Competing interests

The authors declare that this work does not involve competing interests. 


\section{Authors' contributions}

YFL and WJJ conceived and designed the study. The manuscript was written by YFL and HCQ. The manuscript was revised by JS. All authors read and approved the final manuscript.

\section{Acknowledgments}

We acknowledged the reviewers for making significant revision of the manuscript.

Received: 25 June 2015 Accepted: 18 November 2015

Published online: 18 February 2016

\section{References}

1. Bederson JB, Connolly EJ, Batjer HH, Dacey RG, Dion JE, Diringer MN, et al. Guidelines for the management of aneurysmal subarachnoid hemorrhage: A statement for healthcare professionals from a special writing group of the Stroke Council, American Heart Association. Stroke. 2009;40:994-1025.

2. Lovelock CE, Rinkel GJ, Rothwell PM. Time trends in outcome of subarachnoid hemorrhage: Population-based study and systematic review. Neurology. 2010;74:1494-501.

3. Murayama Y, Malisch T, Guglielmi G, Mawad ME, Vinuela F, Duckwiler GR, et al. Incidence of cerebral vasospasm after endovascular treatment of acutely ruptured aneurysms: Report on 69 cases. J Neurosurg. 1997;87:830-5.

4. Yalamanchili K, Rosenwasser RH, Thomas JE, Liebman K, McMorrow C, Gannon P. Frequency of cerebral vasospasm in patients treated with endovascular occlusion of intracranial aneurysms. AJNR Am J Neuroradiol. 1998;19:553-8.

5. Charpentier C, Audibert G, Guillemin F, Civit T, Ducrocq X, Bracard S, et al. Multivariate analysis of predictors of cerebral vasospasm occurrence after aneurysmal subarachnoid hemorrhage. Stroke. 1999;30:1402-8.

6. Keyrouz SG, Diringer MN. Clinical review: Prevention and therapy of vasospasm in subarachnoid hemorrhage. Crit Care. 2007;11:220.

7. Castanares-Zapatero D, Hantson P. Pharmacological treatment of delayed cerebral ischemia and vasospasm in subarachnoid hemorrhage. Ann Intensive Care. 2011;1.

8. Velat GJ, Kimball MM, Mocco JD, Hoh BL. Vasospasm after aneurysmal subarachnoid hemorrhage: Review of randomized controlled trials and meta-analyses in the literature. World Neurosurg. 2011;76:446-54.

9. Raya AK, Diringer MN. Treatment of subarachnoid hemorrhage. Crit Care Clin. 2014;30:719-33.

10. Rabinstein AA, Lanzino G, Wijdicks EF. Multidisciplinary management and emerging therapeutic strategies in aneurysmal subarachnoid haemorrhage. Lancet Neurol. 2010;9:504-19.

11. MacKenzie M, Gorman SK, Doucette S, Green R. Incidence of and factors associated with manipulation of nimodipine dosage in patients with aneurysmal subarachnoid hemorrhage. Can J Hosp Pharm. 2014;67:358-65.

12. Hänggi D, Perrin J, Eicker S, Beseoglu K, Etminan N, Kamp MA, et al. Local delivery of nimodipine by Prolonged-Release microparticles-feasibility, effectiveness and Dose-Finding in experimental subarachnoid hemorrhage. PLoS One. 2012;7, e42597.

13. Ott S, Jedlicka S, Wolf S, Peter M, Pudenz C, Merker P, et al. Continuous selective intra-arterial application of nimodipine in refractory cerebral vasospasm due to aneurysmal subarachnoid hemorrhage. Biomed Res Int. 2014:2014:970741.

14. Kronvall E, Undren P, Romner B, Saveland H, Cronqvist M, Nilsson OG. Nimodipine in aneurysmal subarachnoid hemorrhage: A randomized study of intravenous or peroral administration. J Neurosurg. 2009;110:58-63.

15. Onal MB, Civelek E, Kircelli A, Solmaz I, Ugurel S, Narin F, et al. Comparison of nimodipine delivery routes in cerebral vasospasm after subarachnoid hemorrhage: An experimental study in rabbits. Acta Neurochir Suppl. 2011;110:23-8.

16. Wang F, Yin Y, Jia F, Jiang J. Effects of Topical Administration of Nimodipine on Cerebral Blood Flow following Subarachnoid Hemorrhage in Pigs. J Neurotrauma. 2013;30:591-6.

17. Hoh BL, Ogilvy CS. Endovascular treatment of cerebral vasospasm: Transluminal balloon angioplasty, intra-arterial papaverine, and intra-arterial nicardipine. Neurosurg Clin N Am. 2005:16:501-16.

18. Huang $R$, Jiang F, Feng $Z$, Wang T. Nicardipine in the treatment of aneurysmal subarachnoid haemorrhage: A meta-analysis of published data. Acta Neurol Belg. 2013;113:3-6.
19. Jun P, Ko NU, English JD, Dowd CF, Halbach W, Higashida RT, et al. Endovascular treatment of medically refractory cerebral vasospasm following aneurysmal subarachnoid hemorrhage. AJNR Am J Neuroradiol. 2010:31:1911-6.

20. Stuart RM, Helbok R, Kurtz P, Schmidt M, Fernandez L, Lee K, et al. High-dose intra-arterial verapamil for the treatment of cerebral vasospasm after subarachnoid hemorrhage: Prolonged effects on hemodynamic parameters and brain metabolism. Neurosurgery. 2011;68:337-45. 345.

21. Flexman AM, Ryerson CJ, Talke PO. Hemodynamic stability after intraarterial injection of verapamil for cerebral vasospasm. Anesth Analg. 2012;114:1292-6.

22. Mikeladze KG, Eliava S, Shekhtman OD, Lubnin A, Tabasaranskii TF, lakovlev SB. Intra-arterial injection of verapamil in treatment of cerebral vasospasm in a patient with acute subarachnoid hemorrhage from an aneurysm: Case report. Zh Vopr Neirokhir Im N N Burdenko. 2013;77:57-60. 60.

23. Keuskamp J, Murali R, Chao KH. High-dose intraarterial verapamil in the treatment of cerebral vasospasm after aneurysmal subarachnoid hemorrhage. J Neurosurg. 2008;108:458-63.

24. Muroi C, Seule M, Mishima K, Keller E. Novel treatments for vasospasm after subarachnoid hemorrhage. Curr Opin Crit Care. 2012;18:119-26.

25. Schirmer $\mathrm{CM}$, Hoit DA, Malek AM. latrogenic vasospasm in carotid artery stent angioplasty with distal protection devices. Neurosurg Focus. 2008;24, E12.

26. Liu J, Yao G, Zhou H, Jiang X, Xie P. Clinical investigation of fasudil for the prevention of cerebral vasospasm in extracranial carotid artery stenting. Cell Biochem Biophys. 2014;68:185-8.

27. Satoh S, Takayasu M, Kawasaki K, Ikegaki I, Hitomi A, Yano K, et al. Antivasospastic effects of hydroxyfasudil, a Rho-Kinase inhibitor, after subarachnoid hemorrhage. J Pharmacol Sci. 2012;1 18:92-8.

28. Naraoka M, Munakata A, Matsuda N, Shimamura N, Ohkuma H. Suppression of the Rho/Rho-kinase pathway and prevention of cerebral vasospasm by combination treatment with statin and fasudil after subarachnoid hemorrhage in rabbit. Transl Stroke Res. 2013;4:368-74.

29. Liu GJ, Wang ZJ, Wang YF, Xu LL, Wang XL, Liu Y, et al. Systematic assessment and meta-analysis of the efficacy and safety of fasudil in the treatment of cerebral vasospasm in patients with subarachnoid hemorrhage. Eur J Clin Pharmacol. 2012;68:131-9.

30. Taccone FS, Castanares-Zapatero D, Peres-Bota D, Vincent UL, Berre' J, Melot C. Cerebral autoregulation is influenced by carbon dioxide levels in patients with septic shock. Neurocrit Care. 2010;12:35-42.

31. van den Bergh WM, Dijkhuizen RM, Rinkel GJ. Potentials of magnesium treatment in subarachnoid haemorrhage. Magnes Res. 2004;17:301-13.

32. Ortega-Gutierrez $\mathrm{S}$, Mayer SA. Is the magnesium era for aneurysmal subarachnoid hemorrhage over? Curr Neurol Neurosci Rep. 2010;10:420-2.

33. Diringer MN, Bleck TP, Claude HJR, Menon D, Shutter L, Vespa P, et al. Critical care management of patients following aneurysmal subarachnoid hemorrhage: Recommendations from the Neurocritical Care Society's Multidisciplinary Consensus Conference. Neurocrit Care. 2011;15:211-40.

34. van den Bergh WM, Algra A, van Kooten F, Dirven CM, van Gijn J, Vermeulen $\mathrm{M}$, et al. Magnesium sulfate in aneurysmal subarachnoid hemorrhage: A randomized controlled trial. Stroke. 2005:36:1011-5.

35. Golan E, Vasquez DN, Ferguson ND, Adhikari NKJ, Scales DC. Prophylactic magnesium for improving neurologic outcome after aneurysmal subarachnoid hemorrhage: Systematic review and meta-analysis. J Crit Care. 2013;28:173-81.

36. Bradford CM, Finfer S, O'Connor A, Yarad E, Firth R, McCallister R, et al. A randomised controlled trial of induced hypermagnesaemia following aneurysmal subarachnoid haemorrhage. Crit Care Resusc. 2013;15:119-25.

37. Endo A, Kuroda M, Tanzawa K. Competitive inhibition of 3-hydroxy-3methylglutaryl coenzyme a reductase by ML-236A and ML-236B fungal metabolites, having hypocholesterolemic activity. FEBS Lett. 1976;72:323-6.

38. Bautista C. Unresolved issues in the management of aneurysmal subarachnoid hemorrhage. AACN Adv Crit Care. 2012;23:175-85.

39. Yamada M, Huang Z, Dalkara T, Endres M, Laufs U, Waeber C, et al. Endothelial nitric oxide synthase-dependent cerebral blood flow augmentation by L-arginine after chronic statin treatment. J Cereb Blood Flow Metab. 2000;20:709-17.

40. Vergouwen MD, de Haan RJ, Vermeulen M, Roos YB. Effect of statin treatment on vasospasm, delayed cerebral ischemia, and functional outcome in patients with aneurysmal subarachnoid hemorrhage: A systematic review and meta-analysis update. Stroke. 2010;41:e47-52.

41. Garg K, Sinha S, Kale SS, Chandra PS, Suri A, Singh MM, et al. Role of simvastatin in prevention of vasospasm and improving functional outcome after aneurysmal sub-arachnoid hemorrhage: A prospective, randomized, double-blind, placebo-controlled pilot trial. Br J Neurosurg. 2013;27:181-6. 
42. Liu J, Chen Q. Effect of statins treatment for patients with aneurysmal subarachnoid hemorrhage: a systematic review and meta-analysis of observational studies and randomized controlled trials. Int J Clin Exp Med. 2015;8(5):7198-208.

43. Kumral A, Ozer E, Yilmaz O, Akhisaroglu M, Gokmen N, Duman N, et al. Neuroprotective effect of erythropoietin on hypoxic-ischemic brain injury in neonatal rats. Biol Neonate. 2003;83:224-8.

44. Turner JD, Mammis A, Prestigiacomo CJ. Erythropoietin for the treatment of subarachnoid hemorrhage: A review. World Neurosurg. 2010;73:500-7.

45. Jerndal M, Forsberg K, Sena ES, Macleod MR, O'Collins VE, Linden T, et al. A systematic review and meta-analysis of erythropoietin in experimental stroke. J Cereb Blood Flow Metab. 2010;30:961-8.

46. Turner JD, Mammis A, Prestigiacomo CJ. Erythropoietin for the treatment of subarachnoid hemorrhage: A review. World Neurosurg. 2010;73:500-7.

47. Güresir E, Vasiliadis N, Konczalla J, Raab P, Hattingen E, Seifert V, et al. Erythropoietin prevents delayed hemodynamic dysfunction after subarachnoid hemorrhage in a randomized controlled experimental setting. J Neurol Sci. 2013;332:128-35.

48. Ding D, Starke RM, Dumont AS, Owens GK, Hasan DM, Chalouhi N, et al. Therapeutic implications of estrogen for cerebral vasospasm and delayed cerebral ischemia induced by aneurysmal subarachnoid hemorrhage. BioMed Res Int. 2014;2014:1-9.

49. Lin CL, Dumont AS, Wu SC, Wang CJ, Howng SL, Huang YF, et al. 17Betaestradiol inhibits endothelin-1 production and attenuates cerebral vasospasm after experimental subarachnoid hemorrhage. Exp Biol Med (Maywood). 2006;231:1054-7.

50. Lin CL, Shih HC, Dumont AS, Kassell NF, Lieu AS, Su YF, et al. The effect of 17beta-estradiol in attenuating experimental subarachnoid hemorrhageinduced cerebral vasospasm. J Neurosurg. 2006;104:298-304.

51. Srivastava S, Weitzmann MN, Cenci S, Ross FP, Adler S, Pacifici R. Estrogen decreases TNF gene expression by blocking JNK activity and the resulting production of c-Jun and JunD. J Clin Invest. 1999;104:503-13.

52. Lee SY, Andoh T, Murphy DL, Chiueh CC. 17Beta-estradiol activates ICI 182,780-sensitive estrogen receptors and cyclic GMP-dependent thioredoxin expression for neuroprotection. FASEB J. 2003;17:947-8.

53. Burmester T, Weich B, Reinhardt S, Hankeln T. A vertebrate globin expressed in the brain. Nature. 2000;407:520-3.

54. De Marinis E, Acaz-Fonseca E, Arevalo MA, Ascenzi P, Fiocchetti M, Marino $\mathrm{M}$, et al. 17Beta-Oestradiol anti-inflammatory effects in primary astrocytes require oestrogen receptor beta-mediated neuroglobin up-regulation. J Neuroendocrinol. 2013;25:260-70.

55. Lin CL, Dumont AS, Tsai YJ, Huang JH, Chang KP, Kwan AL, et al. 17Betaestradiol activates adenosine $\mathrm{A}(2 \mathrm{a})$ receptor after subarachnoid hemorrhage. J Surg Res. 2009;157:208-15.

56. Kao CH, Chang CZ, Su YF, Tsai YJ, Chang KP, Lin TK, et al. 17Beta-Estradiol attenuates secondary injury through activation of Akt signaling via estrogen receptor alpha in rat brain following subarachnoid hemorrhage. J Surg Res. 2013;183:e23-30.

57. Arakawa Y, Kikuta K, Hojo M, Goto Y, Ishii A, Yamagata S. Milrinone for the treatment of cerebral vasospasm after subarachnoid hemorrhage: Report of seven cases. Neurosurgery. 2001;48:723-8. 728-730.

58. Shankar JJ, Dos SM, Deus-Silva L, Lum C. Angiographic evaluation of the effect of intra-arterial milrinone therapy in patients with vasospasm from aneurysmal subarachnoid hemorrhage. Neuroradiology. 2011;53:123-8.

59. Anand S, Goel G, Gupta V. Continuous intra-arterial dilatation with nimodipine and milrinone for refractory cerebral vasospasm. Journal of neurosurgical anesthesiology. 2014;26:92.

60. Chowdhury FH, Haque MR. Severe hypotension, cardiac arrest, and death after intracisternal instillation of papaverine during anterior communicating artery aneurysm clipping. A case report. Acta Neurochir (Wien). 2013;155:281-2.

61. Rahme R, Jimenez L, Pyne-Geithman GJ, Serrone J, Ringer AJ, Zuccarello M, et al. Endovascular management of posthemorrhagic cerebral vasospasm: Indications, technical nuances, and results. Acta Neurochir Suppl. 2013;115:107-12.

62. Deshaies EM, Boulos AS, Drazin D, Popp AJ. Evidence-based pharmacotherapy for cerebral vasospasm. Neurological Research. 2009;31:615-20.

63. Niu PP, Yang G, Xing YQ, Guo ZN, Yang Y. Effect of cilostazol in patients with aneurysmal subarachnoid hemorrhage: A systematic review and metaanalysis. J Neurol Sci. 2014;336:146-51.

64. Shimamura N, Ohkuma H. Phenotypic transformation of smooth muscle in vasospasm after aneurysmal subarachnoid hemorrhage. Transl Stroke Res. 2014:5:357-64
65. Siasios I, Kapsalaki EZ, Fountas KN. Cerebral vasospasm pharmacological treatment: An update. Neurology Research International. 2013;2013:1-20.

66. Vatter $H$, Zimmermann M, Tesanovic V, Raabe A, Schilling L, Seifert V. Cerebrovascular characterization of clazosentan, the first nonpeptide endothelin receptor antagonist clinically effective for the treatment of cerebral vasospasm. Part I: Inhibitory effect on endothelin(A) receptormediated contraction. J Neurosurg. 2005;102:1101-7.

67. Povlsen GK, Edvinsson L. MEK1/2 inhibitor U0126 but not endothelin receptor antagonist clazosentan reduces upregulation of cerebrovascular contractile receptors and delayed cerebral ischemia, and improves outcome after subarachnoid hemorrhage in rats. J Cereb Blood Flow Metab. 2015;35: 329-37.

68. Shen J, Pan JW, Fan ZX, Xiong XX, Zhan RY. Dissociation of vasospasmrelated morbidity and outcomes in patients with aneurysmal subarachnoid hemorrhage treated with clazosentan: A meta-analysis of randomized controlled trials. J Neurosurg. 2013;119:180-9.

69. Macdonald RL, Higashida RT, Keller E, Mayer SA, Molyneux A, Raabe A, et al. Randomised trial of clazosentan, an endothelin receptor antagonist, in patients with aneurysmal subarachnoid hemorrhage undergoing surgical clipping (CONSCIOUS-2). Acta Neurochir Suppl. 2013;115:27-31.

70. Kim H, Britton GL, Peng T, Holland CK, McPherson DD, Huang SL. Nitric oxide-loaded echogenic liposomes for treatment of vasospasm following subarachnoid hemorrhage. Int J Nanomedicine. 2014;9:155-16579.

71. Fathi AR, Bakhtian KD, Pluta RM. The role of nitric oxide donors in treating cerebral vasospasm after subarachnoid hemorrhage. Acta Neurochir Suppl. 2011;110:93-7.

72. Clatterbuck RE, Gailloud P, Tierney T, Clatterbuck VM, Murphy KJ, Tamargo RJ. Controlled release of a nitric oxide donor for the prevention of delayed cerebral vasospasm following experimental subarachnoid hemorrhage in nonhuman primates. J Neurosurg. 2005;103:745-51.

73. Garry PS, Ezra M, Rowland MJ, Westbrook J, Pattinson KTS. The role of the nitric oxide pathway in brain injury and its treatment — From bench to bedside. Experimental Neurology. 2015;263:235-43.

74. Sehba FA, Schwartz AY, Chereshnev I, Bederson JB. Acute decrease in cerebral nitric oxide levels after subarachnoid hemorrhage. J Cereb Blood Flow Metab. 2000;20:604-11.

75. Radi R. Peroxynitrite, a stealthy biological oxidant. J Biol Chem. 2013;288: 26464-72

76. Simard JM, Aldrich EF, Schreibman D, James RF, Polifka A, Beaty N. Low-dose intravenous heparin infusion in patients with aneurysmal subarachnoid hemorrhage: a preliminary assessment. J Neurosurg. 2013;1 19:1611-1619.

77. Wurm G, Tomancok B, Nussbaumer K, Adelwöhrer C, Holl K. Reduction of ischemic sequelae following spontaneous subarachnoid hemorrhage: a double-blind, randomizedcomparison of enoxaparin versus placebo. Clin Neurol Neurosurq. 2004;106:97-103.

78. Yamamoto T, Esaki T, Nakao Y, Mori K. Efficacy of low-dose tissueplasminogen activator intracisternal administration for the prevention of cerebral vasospasm after subarachnoid hemorrhage. World Neurosurg. 2010; 73:675-82.

79. Etminan N, Beseoglu K, Eicker SO, Turowski B, Steiger HJ, Hänggi D. Prospective, randomized, open-label phase II trial on concomitant intraventricular fibrinolysis and low-frequencyrotation after severe subarachnoid hemorrhage. Stroke. 2013;44:2162-8.

\section{Submit your next manuscript to BioMed Central and we will help you at every step:}

- We accept pre-submission inquiries

- Our selector tool helps you to find the most relevant journal

- We provide round the clock customer support

- Convenient online submission

- Thorough peer review

- Inclusion in PubMed and all major indexing services

- Maximum visibility for your research

Submit your manuscript at www.biomedcentral.com/submit
( ) BioMed Central 